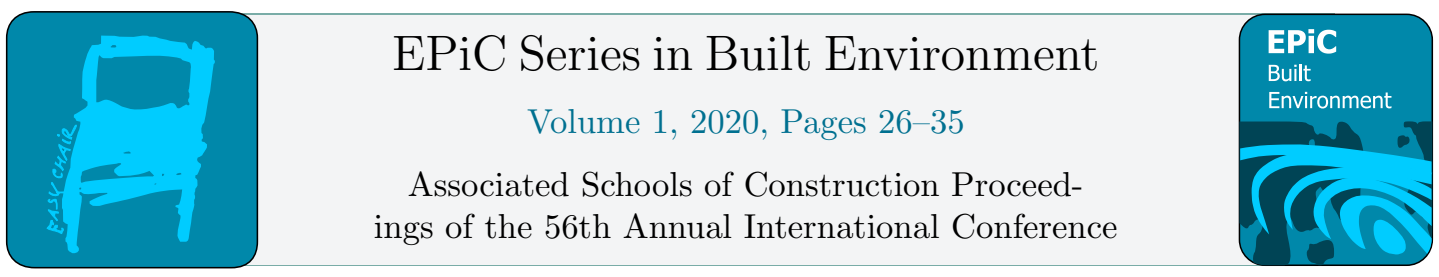

\title{
Teaching Construction Planning and Scheduling: Why, What, When, and How.
}

\author{
Ihab Mohammad Hamdi Saad, Ph.D. \\ Northern Kentucky University \\ Highland Heights, Kentucky
}

\begin{abstract}
Construction planning and scheduling are two of the essential skills required in a construction project manager. Planning and scheduling courses are a core component of any construction program, and constitute one of the major learning outcomes to be achieved and documented by a construction program to earn and maintain its accreditation by ACCE. Many universities follow different approaches towards developing and delivering the knowledge required for these two skills. This paper investigates the current practices among different construction programs in the US, together with suggestions for the future, responding to the latest developments in the industry. The content, timing, and reason for including this content are explained through this paper, together with suggestions for the method of delivery and adjustments to be made moving forward. The paper presents the results and analysis of a survey sent to construction educators in the US related to the current practices of teaching planning and scheduling related to the content, number of courses, topics discussed, and qualifications of the instructors.
\end{abstract}

Key Words: Planning, Scheduling, Technology, Construction Management, Curriculum.

\section{Introduction}

Time management is one of the essential skills a project manager must exhibit in his/her work. The Project Management Institute (PMI) lists it as one of the ten areas of knowledge in project management (PMI 2019). This topic is usually delivered in undergraduate construction engineering/management education under the title of construction project planning and scheduling. When mentioned together, planning is defined as "the establishment of goals, policies, and procedures for a social or economic unit", whereas scheduling is defined as "a procedural plan that indicates the time and sequence of each operation" (Merriam-Webster Dictionary). Project planning was defined as "the process of choosing the one method and order of work to be adopted for a project from all the various ways and sequences in which it could be done" (Antill and Woodhead, 1990). In this sense, planning is a predecessor to scheduling, and scheduling is a by-product of planning. However, when mentioned separately, the two terms are often used interchangeably to designate steps and activities 
taken to manage time aspects of a project. The PMI prescribes a structured approach to time management consisting of six major and mostly consecutive processes:

1- Activity Definition

2- Activity Sequencing

3- Activity Resource Estimating

4- Activity Duration Estimating

5- Schedule Development

6- And Schedule Control

This paper addresses the reasons justifying teaching construction planning and scheduling as part of a construction engineering/management curriculum, together with the main components of a course(s) delivering this topic, the timing within the curriculum, and a suggested approach to delivering this information.

\section{Literature Review}

Time management, in addition to being a necessary component of a project management plan, is part of the project triple constraint: Time, Cost, and Quality or Scope (Dobson, 2004). It is also a "discipline performed by every person, every day" (O’brien and Plotnick, 2006). Several researchers have highlighted the direct impact of successful project planning and scheduling on overall project success (Galvin et al., 2014) (Rahrovani et al., 2014) (Cooke-Davies, 2002). A Client or Owner will expect the project to be completed within the allotted time, at or below budget, and meeting or exceeding the specified quality requirements. These three elements are mutually interdependent: in order to avoid a delay, additional costs are expected to be spent in order to expedite the project, and rushing work to recover from that delay might affect the expected quality. The link between the estimate and the budget is the schedule that attempts to predict when will the money be spent, when will it be collected, what is the gap in between, and provides suggestions for bridging this gap through different financing schemes (PMI, 2017). Equipment management and labor productivity including the coordination between the numbers of crews interacting with different pieces of equipment to achieve optimum production cannot be achieved without synchronizing cycle times with production rates (Saad, 2018). Subcontractor management including space hand-over and sharing among different trades necessitates a clear visual understanding of space and logistics minimizing any conflicts among field crews (Seppanen et al., 2010). In a recently published research about the curriculum of the future, both academics and professionals agreed that construction planning and scheduling are among the more creative skills that are not likely to be replaced by a machine in the near future (Saad, 2019).

\section{Methodology}

In order to gauge current practices of teaching construction planning and scheduling in US academic programs, a survey was designed and disseminated online to Colleges and Universities accredited by the American Council for Construction Education (ACCE). The survey was sent via the Associated Schools of Construction (ASC) mailing list to academics. Of the 75 accredited US members, responses were received from 42 , or about $56 \%$ of the accredited programs. In addition to questions about demographics (Name of College, Program size, Number of planning and scheduling courses offered), questions were asked about the contents of the course(s) and the timing of offering them within the curriculum. Respondents were also asked about work experience requirements in the form 
of internships or co-ops, and whether they offered any sub-specialties within their programs. The results of the survey were analyzed and the findings presented herein. The survey questions addressed which topics were taught in planning and scheduling classes, how many classes addressed the topic within the program, what technology (software) was used to facilitate instruction. Other questions about demographics included the rank and title of the instructor(s), and for how many years have they been teaching the subject.

\section{Results and Analysis}

The paragraphs hereunder provide the results of the survey and answers to the research questions of what subjects are to be taught, how should these subjects be addressed, and when should the planning/scheduling class(es) be offered.

\section{What}

The number of classes and their content varies from one academic program to another. Based on the results of the survey, of the responding 42 academic programs, 14 (39\%) teach one class on the subject, whereas 12 programs (33\%) offer two classes, and 10 programs (28\%) offer more than two classes.

As for the contents, 35 (83\%) programs indicated that they provide instruction on the development of a Work Breakdown Structure (WBS), which is the precursor to developing an activity list. Only 20 programs (48\%) still offer instruction on the traditional though outdated network technique Arrow Diagramming Method (ADM). On the other hand, the vast majority of programs, 37 (88\%) emphasize the Precedence Diagramming Method (PDM), and 35 (83\%) provide instruction on manual Critical Path Method (CPM) calculations. Fewer programs, 16 (38\%), address the topic of scheduling under uncertainty or probabilistic scheduling including Program Evaluation and Review Technique (PERT). More than half of the responding programs, $25(60 \%)$, provide instruction on linear scheduling methods including Line of Balance (LOB). Only 3 programs (7\%) provided instruction on very short term scheduling and crew-equipment interaction in the form of Multiple activity Charts (MAC), whereas a larger number, 22 (52\%) provided instruction on Pull Planning, which is an element of lean construction, including Last Planner, Reverse Phase Scheduling, and Flow scheduling. Table 1 shows the results of the survey on planning/Scheduling topics.

Table 1

Planning and Scheduling Topics Addressed in Class

\begin{tabular}{|c|l|c|c|}
\hline$\#$ & \multicolumn{1}{|c|}{ Answer } & Count & $\%$ \\
\hline 1 & Work Breakdown Structure (WBS) Development & 35 & 83.33 \\
\hline 2 & Arrow Diagramming Method (ADM or AOA) & 20 & 47.62 \\
\hline 3 & Precedence Diagramming Method (PDM) & 37 & 88.10 \\
\hline 4 & Network Calculations (CPM) & 35 & 83.33 \\
\hline 5 & Probabilistic Scheduling (PERT) & 16 & 38.10 \\
\hline 6 & Linear Scheduling (Line of Balance or Similar Techniques) & 25 & 59.52 \\
\hline 7 & Resource Management & 32 & 76.19 \\
\hline 8 & Cash Flow Projections / Management & 29 & 69.05 \\
\hline 9 & Earned Value Analysis (EVA) & 26 & 61.90 \\
\hline 10 & Time Compression (Project Crashing) & 31 & 73.81 \\
\hline 11 & Schedule Updating / Management & 33 & 78.57 \\
\hline
\end{tabular}




\begin{tabular}{|c|l|c|c|}
\hline 12 & Multiple Activity Charts (MAC) & 3 & 7.14 \\
\hline 13 & Pull Planning (Last Planner, RPS, Flow) & 22 & 52.38 \\
\hline 14 & Other & 10 & 23.81 \\
\hline
\end{tabular}

Computerized scheduling was addressed by all surveyed programs, with 15 programs (22\%) indicating they are using Microsoft Excel as the primary software. 25 programs (37\%) reported using Microsoft Project, 18 programs (27\%) using Primavera/Oracle P6, 4 programs (6\%) using Asta, one program (1.5\%) using Phoenix, and 4 programs $(6 \%)$ using other packages. Of the surveyed programs, 8 programs $(22 \%)$ indicated that they dedicate less than 5 instruction/lab hours for software instruction/training, 11 programs (31\%) provided between 5 and 10 hours, 7 programs (19\%) provided 11 to 15 hours, and 10 programs (28\%) provided more than 15 hours of software instruction/training. Table 2 shows the distribution of software used in scheduling instruction.

Table 2

Software Used in Scheduling Instruction

\begin{tabular}{|c|c|c|c|}
\hline$\#$ & Software Used & $\%$ & Count \\
\hline 1 & Microsoft Excel & 22.39 & 15 \\
\hline 2 & Microsoft Project & 37.31 & 25 \\
\hline 3 & Primavera/Oracle P6 & 26.87 & 18 \\
\hline 4 & Phoenix & 1.49 & 1 \\
\hline 5 & Asta & 5.97 & 4 \\
\hline 6 & Other & 5.97 & 4 \\
\hline
\end{tabular}

When it comes to schedule details and the link between the schedule and other project functions, 32 (76\%) pf the programs addressed resource management, with 29 (69\%) providing instruction on cash flow projections and management.

Schedule management and control are essential to successful schedule utilization. 33 programs (79\%) provided instruction on schedule updating/management, and 26 programs (62\%) addressed the link between the project time and its cost in the form of Earned Value Analysis/Management (EVM).

\section{When}

The development of a meaningful schedule requires a familiarity with construction operations. In many cases the first opportunity to obtain this familiarity is through work experience. Many programs have a work experience requirement in the form of internships, co-ops, or summer employment. The work experience usually starts following the freshman year, and allows students to be exposed to the industry at both the field and office operations. Hauck et al. (2000), and Panthi et al. (2017) highlighted the impact of internships and co-ops on student performance. Although the first research observed only $1 \%$ improvement in student performance, the second one was more pronounced about the impact of work experience on student retention and performance in general. Among the most cited activities assigned to students during internships and co-ops was planning and scheduling, including schedule maintenance and updates. In their response to the survey, 27 programs $(64 \%)$ indicated they have a work experience as a formal requirement for the degree, whereas 4 programs $(9 \%)$ indicated that work experience is highly advisable, though not a requirement for the degree, and 11 programs (26\%) indicated that they do not require any work experience for offering 
the degree. Of the programs requiring work experience, 2 programs ( $8 \%$ ) required 150 hours or less, 2 programs (8\%) required between 151 and 300 hours, 9 programs (39\%) required between 301 and 600 hours, and 10 programs (44\%) required more than 600 hours. These hours can be accumulated during consecutive summers, or during the regular semesters and have to be authenticated by employer representatives. 8 programs (35\%) indicated that the planning and scheduling class is offered before the work experience, whereas 4 programs (17\%) indicated it is offered during the work experience (the semesters between 2 summers), and a majority of 13 programs (52\%) offers the class(es) after the work experience. The timing of providing the planning and scheduling class(es) is crucial in determining the detailed content of these classes, as students lacking exposure to work experience will be unlikely to grasp the full magnitude of the details involved in schedule development and management. The most reported pre-requisite for the planning and scheduling class was construction estimating/Costing (28\%), followed by materials and methods (22\%), and Contracts/Contract administration (10\%). Other reported pre-requisites include Equipment Management (5\%), Productivity (1\%), Soils and Foundations (5\%), Safety (6\%), Structures and Statics (5\%), and Project Management (5\%). The ability for students to identify the quantities and methods from blueprints through a quantity takeoff, identify labor crew productivity and costs through the estimate, and associate the required details in the schedule from the contract documents highlight that these are essential pre-requisites to developing a meaningful schedule.

\section{How}

This section provides a suggested structure and contents of a project planning and scheduling class based on the results of the survey, and the author's professional experience on the subject. Following the structured approach of the Project Management Institute (PMI), and starting from the first principles, students should be first introduced to the process of decomposition in order to breakdown a complex project into smaller entities. This process breaks down the project into its main systems (Structural, Architectural, Mechanical, Electrical, etc.), then subsystems (HVAC, Plumbing, Communications, Conveying Systems, Finishing, etc.), then work packages (elevators, HVAC ducts, Flooring, Painting, etc.). In a separate document, the work packages are further broken down into activities (place concrete for third floor slab, etc.). This process is achieved through the Work Breakdown Structure (WBS) which is a hierarchical representation of the project decomposition process and, as a rule of thumb, follows the 1-5-5-5 approach (Colodzin, 2009). This means that each level (Project, system, subsystem, etc.) is further broken down into approximately 5 subsequent levels, up to the level of the work package (the last level to appear on the WBS). The work packages are further developed into a detailed activity list including an active verb and a noun for each activity. Other activity attributes can also be developed such as a unique activity ID reflecting its location, responsible party, and any other details unique to the activity and enabling the future production of sub-schedules through filters. This process concludes the first step of time management: Activity Definition. Figure 2 shows a partial WBS developed by students in a junior level construction planning and scheduling class.

Upon developing the activity list, logical relationships linking these activities are established. This can be achieved using either forward chaining (working from the beginning of the project till its end) or backward chaining (starting with the project completion and moving backwards), or both (assigning predecessors and successors to different activities). Different logical relationships are utilized (Finish-to-Start, Start-to-start, Finish-to Finish, and Start-to-Finish), including any necessary 
lags and overlaps among the activities' start and finish events. This process concludes the second step, activity sequencing.

A resource pool is identified based on the availability, the specifications, and the required needs of the project. For each identified resource, its production rate is calculated based on historical data, and available databases and publications (e.g. R.S. Means, Walker's, etc.). Additional resource attributes including the determination of whether it is readily available or it is a long lead item are listed. Upon defining the required resources and their available rates of production, an activity duration estimate follows, based in deterministic calculations on the equation: Duration $=\mathrm{Q}($ Quantity)/P (Production rate).

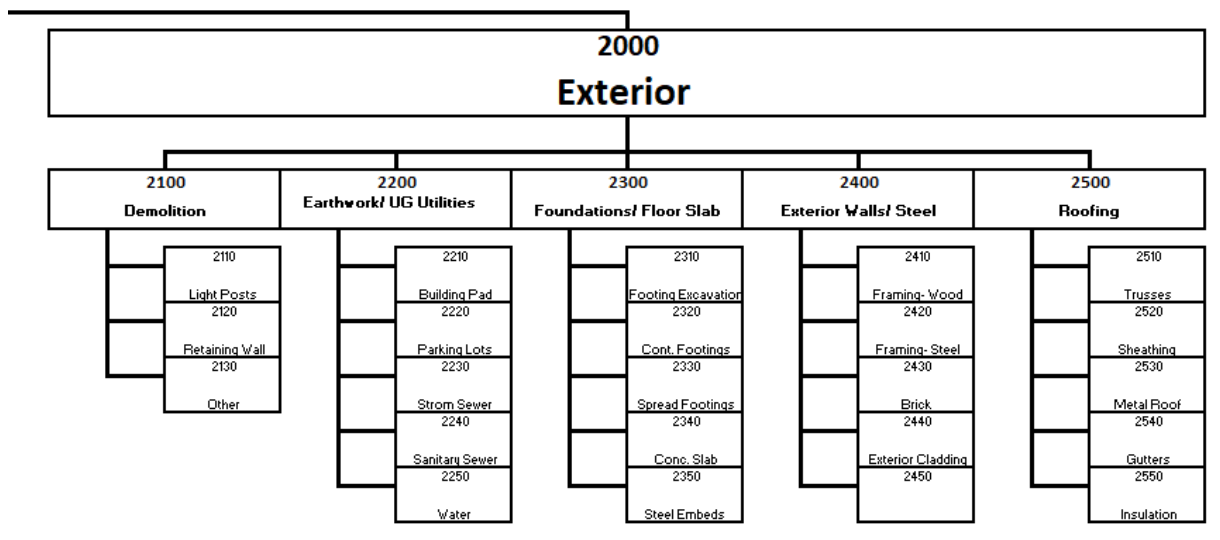

Figure 2. Partial WBS

If probabilistic scheduling is used, the duration is calculated using the equation:

$$
\mathrm{D}=[\mathrm{O} \text { (optimistic) + 4.M.L. (Most likely) }+\mathrm{P}(\text { Pessimistic) })] / 6 .
$$

In case multiple resources are needed for the activity, the lowest-production or slowest resource drives the activity duration. Once activity durations are calculated, the Critical Path Method (CPM) algorithm may be used to determine the critical path, calculate the early and late start and finish dates for the activities, as well as the total and free floats for the non-critical activities. Once the schedule is manually developed and students are familiar with the calculations, data can be entered in the selected software to develop a computerized version of the schedule. Some programs make the mistake of focusing too much on the mechanics of using the software rather than the logic and theory of developing the schedule. This mistake results in producing data-entry personnel who treat the software like a black box, without the ability of critiquing the produced results. In the author's opinion, backed by years of professional experience developing schedules and teaching planning and scheduling classes, introducing the students to manual calculations and understanding the physical meaning of the results allows for a better understanding. It allows the students upon graduation to navigate easily among different software packages as the biggest difference among these packages is the user interface. Figure 3 shows a sample output from a class project using a computer generated schedule. A schedule is only as good as its maintenance, as most schedules in practice will face unexpected changes requiring revisions, and in some cases a complete overhaul. Understanding the concepts of schedule maintenance and updating is crucial to maintaining a working schedule. The concepts of work measurement, percent complete (PCT), elapsed and remaining durations, and 
forecasts for completion allows for proper schedule updating and maintenance. Managing the schedule might also entail time compression, therefore the concepts of activity cost slopes and which activities are the best candidates for expediting or "crashing" in order to restore the schedule compliance are presented. Earned Value Management (EVM) connects time and cost aspects of the project. It enables the user to determine the overall project performance by comparing the Planned Value (PV or BCWS), the Earned Value (EV or BCWP) and the Actual Cost (AC or ACWP). The resulting variances (Cost Variance or $\mathrm{CV}$ and Schedule Variance or SV) highlight the periodic project performance while forecasting the expected cost at completion and updated time of completion.

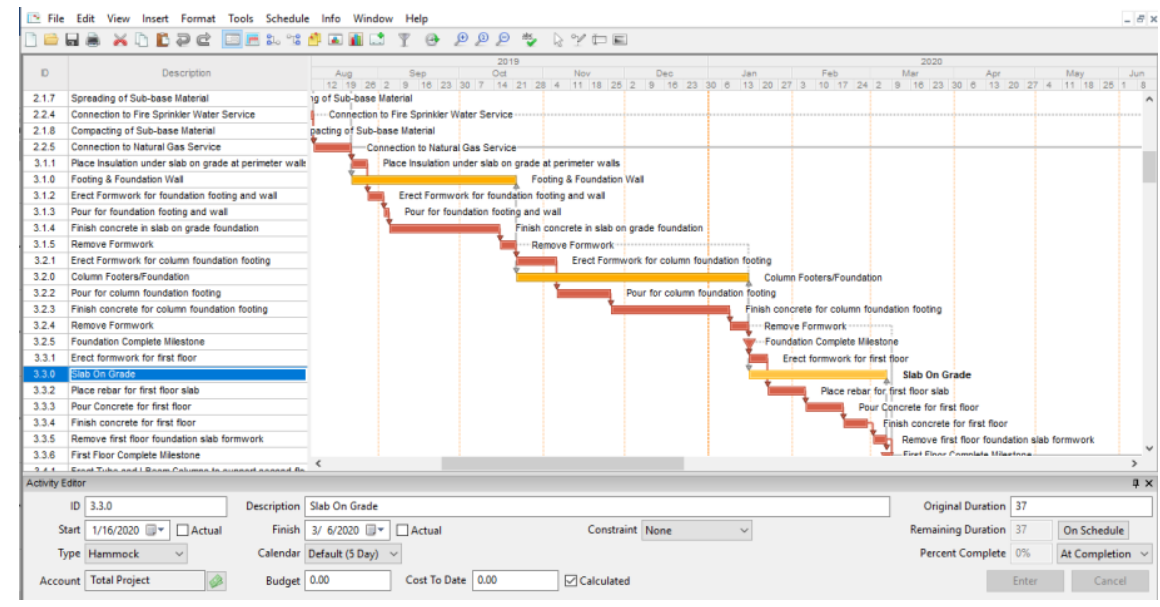

Figure 3. Sample computer-generated schedule

$7(17 \%)$ of the surveyed programs indicated that they offer sub-disciplines or tracks in their programs including residential (4 programs), commercial (5), heavy civil/highways (5), health care (1), specialty systems (Electrical and HVAC) (1), and demolition (1). For these specialized disciplines, particularly those involving linear or repetitive construction (highways, pipelines, high-rise residential, etc.) the introduction of linear scheduling techniques is highly recommended. Line of Balance (LOB) is one of the techniques allowing for scheduling such projects, and emphasizes the fact that equilibrium among consecutive activities while providing proper buffers allows for a balanced workforce, and faster project completion (Arditi et al., 2002). Lean construction adopts these concepts by shifting from local optimization on certain activities to focusing on the throughput of the schedule (Tommelein et al., 1999). The goal is to transition schedule development from a topdown approach performed by project executives to a bottom-up approach where the details of the schedule are developed by the individuals performing the job on the ground, or the last-planners. There is currently a departure from the old school where a Client (Owner) insisted on obtaining a complete master schedule prior to the start of work, following the famous saying: Let's start with a solid plan. With practice, it was shown that solid, sometimes rigid, plans get broken easily, and that the solution is to have a fluid plan that can adapt to changes without being broken. Integrated project delivery (IPD) and collaborative interaction among the project stakeholders ushered in a new wave of planning, focusing at the beginning of the project on negotiating a milestone schedule outlining the major dates in the project, while filling the details at a later stage. These details are filled in the form of look-ahead schedules covering a time span between 6 to 8 weeks, and providing recovery from any delays on a regular basis before moving to the next milestone. Last Planner (LP) scheduling 
approach, sometimes called pull planning or reverse phase scheduling (RPS) focuses on promises among the process performers, and percent plan completion (PPC), handing over the work and the space thereabout to the next performer (Frandson et al., 2014). Teaching these concepts in the classroom requires familiarity with the short-term planning, crew-balancing, and operational details which can only be obtained through work experience. Therefore it is recommended that this practical aspect of scheduling be discussed only after students have undergone an internship or an element of work experience allowing them to grasp the inherent details. Figure 4 depicts a partial linear schedule reflecting the repetitive operations in a multi-story concrete structure construction.

26 of the surveyed programs (62\%) indicated that they believe graduates will be capable of developing meaningful schedule upon graduation, whereas 15 (36\%) answered "Maybe" to this question, and $4(10 \%)$ answered "No". In a follow-up question, 30 programs $(71 \%)$ believed that their graduates will learn more about planning and scheduling on the job than what they learned in the classroom, with 8 (19\%) answering "Maybe", and 4 answering "No", as displayed in Table 3.

Table 3

Perceptions about continuous learning on the job

\begin{tabular}{|c|c|c|c|}
\hline$\#$ & Answer & $\%$ & Count \\
\hline 1 & Yes & & 30 \\
\hline 2 & Maybe & & 8 \\
\hline 3 & No & & 4 \\
\hline & Total & $100 \%$ & 42 \\
\hline
\end{tabular}

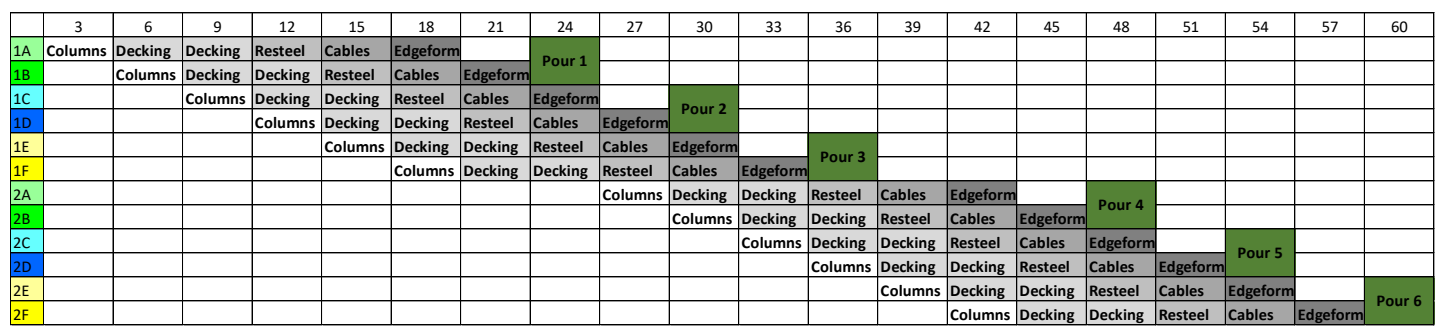

Figure 4. Linear schedule for multi-story concrete structure

\section{Conclusions}

Planning and scheduling are necessary requirements for project success, and indispensable skills for construction management students. These skills and the knowledge underlying them need to be delivered in a progressively developed fashion building on other acquired skills ranging from blueprint reading to quantity takeoff to contract administration. Some of the basic knowledge needs to address the theory behind it, and is reinforced through work experience at both the field operations and project management levels. It is essential to teach the future generation of planners and schedulers how to "think" about these skills and how to understand the logic of the operations rather than mere data-entry in the use of computer software. Mastery of software skills is complementary to this theoretical understanding, but should not be a goal in and of itself. The goal of providing the planning and scheduling instruction is to create a life-long learners who can adapt, conform to, and ultimately lead changes in scheduling methods and approaches that will be eventual in the near future. 
Graduates will learn more about project planning and scheduling on the job than what they have learned in the classroom. This necessitates an open-minded attitude to convert the work experience and observations therein into best practices allowing for future growth. Focusing on bottom-up scheduling is essential as it is gradually replacing the old top-down schedule development with minimum input from the actual performers. Principles of collaboration and lean construction provide the flexibility to adapt the schedule to unforeseen events and result in less confrontational and more successful project outcomes. As the field of construction planning and scheduling is rapidly evolving with the implementation of new construction technology, the use of new software, and adopting new paradigms (Flow, RPS, etc.), a follow-up research should build on the findings of this survey and adapt the planning and scheduling instruction to the new developments. As previously mentioned, the cyclical nature of this review should ideally coincide with the accreditation cycle of no more than six years.

\section{References}

A Guide to the Project Management Body of Knowledge (PMBOK), 6th edition, Project Management institute (PMI), ISBN: 978-1-62825-184-5, 2017

Antill, J., Woodhead, R., Critical Path Methods in Construction Practice, 4th Edition, NY, Wiley Publishers, 1990

Arditi, D., Tokdemir, O., Suh, K., Challenges in Line-of-Balance Scheduling, Journal of Construction Engineering and Management, ASCE, Vol.128 Issue 6, December 2002

Colodzin, M., The Five Secrets of Project Scheduling, PMI Virtual Library, www.PMI.org, 2009

Dobson, M., The Triple Constraints in Project Management, Project Management Essential Library Series, Vienna: Management Concepts, Inc., 2004

Frandson, A., Berghede, K., Tommelein, I., Takt-Time Planning and the Last Planner, Proceedings of the International Group of Lean Construction ILGC, Oslo, Norway, pp 571-580, June 2014

Galvin, T., Gibbs, M., Sullivan, J., Williams, C., Leadership competencies of project managers: An empirical study of emotional, intellectual, and managerial dimensions, Journal of Economic Development, Management, IT, Finance, and Marketing, 6(1), 35, 2014

Hauck, A., Allen, S., Rondinelli, D., Impact of Structured Internship Programs on Student Performance in Construction Management Curricula, Journal of Construction Education, 5 (3), pp 272-287, 2000

https://www.merriam-webster.com/dictionary/planning

O’Brien, J., Plotnick, F., CPM in Construction Management, 6th Edition, McGraw Hill, 2006

Panthi, K., Hollar, D., Wang, G., Work Experience Requirement and Expectation of Construction Management Students in ACCE Accredited Construction Management Programs, Proceedings of the 125th International Conference and Exhibition, American Society of Engineering Education ASEE, 2018

Rahrovani, Y., Chan, Y. E., Pinsonneault, A., Determinants of IS Planning Comprehensiveness, Communications of the Association for ISs, 34(59), 1133-1155, 2014

Cooke-Davies, T., The Real Success Factors on Project, International Journal of Project Management, 20, pp. 185-190, 2002

Saad, I., The Multiple Activity Chart (MAC): A Multi-faceted tool for Project Planning and

Control, 54 $4^{\text {th }}$ international annual conference, ASC, Minneapolis, April 2018.

Saad, I., Construction Curriculum of the Future, Proceedings of the $126^{\text {th }}$ International Conference and Exhibition, American Society of Engineering Education ASEE, 2019

Seppanen, O., Ballard, G., Pesonen, S., The Combination of Last Planner System and LocationBased Management System, Lean Construction Journal, pp 45-54, 2010 
Tommelein, I., Riley, D., and Howell, G. "Parade Game: Impact of Work Flow Variability on Trade Performance.” ASCE, Journal of Construction Engineering and Mgmt., 125 (5) 304-310, 1999. 